phase-shift, consider the dipolar structure of solids. In most cases dipoles have two or more equilibrium positions. They oscillate around one equilibrium position with a frequency $\omega_{0} / 2 \pi$, but occasionally they jump into another one. An external field acts in two ways on the dipoles. (i) The dipole direction in the equilibrium positions is changed, and (ii) the distribution of dipoles over the various equilibrium positions is also altered. Let $\tau_{1}$ and $\tau_{2}$ be the times required to establish equilibrium for the two cases. Then in the second case, this time, together with the frequency of the field, entirely determine the frequency-dependence of $\varepsilon_{2}$, which in this case is of the so-called Debye type,

$$
\varepsilon_{2} \propto \frac{\omega \tau_{2}}{1+\omega^{2} \tau_{2}^{2}}
$$

Thus $\varepsilon_{2}$ has a maximum when $\omega=1 / \tau_{2}$. In the first case, however, loss is of the resonance type and is determined not only by $\tau_{1}$, but also by $\omega_{0}$ :

$\varepsilon_{2} \propto \frac{1}{2}\left\{\frac{\omega \tau_{1}}{1+\left(\omega+\omega_{0}\right)^{2} \tau_{1}^{2}}+\frac{\omega \tau_{1}}{1+\left(\omega-\omega_{0}\right)^{2} \tau_{1}{ }^{2}}\right\}$.

In this case $\varepsilon_{2}$ has a maximum when

$$
\omega=\left(1+\omega_{0}^{2} \tau_{1}^{2}\right)^{1 / 2} / \tau_{1} \text {. }
$$

Thus if $\omega_{0} \tau_{1} \ll 1$, both types of loss behave similarly ; but for $\omega_{0} \tau_{1} \gg 1$, the maximum of $\varepsilon_{2}$ in (14) lies always near $\omega_{0}$. This second type of loss is expected to be of importance in the region of ultra-short waves, but detailed comparisons with experiments have not been carried out yet. For longer waves the Debye loss gives, in general, a reasonably good description of experiments if one admits the existence of a whole range of relaxation times $\tau_{2}$. So far, however, in only a few cases has it been possible to calculate the actual value of $\tau_{2}$ from the structure of the solid.

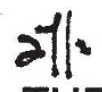

\section{THE FOOD AND AGRICULTURE} ORGANISATION

$\mathrm{T}$ HE Food and sriculture Organisation (F.A.O.) of the Unite 1 ations, on the invitation of the Interim Copphision on Food and Agriculture, held the first sessij of its Conference at Quebec during October 6. November 1, 1945. The report of the proceedings has now been published*.

(1) the formal establishment of the Food and Agriviture Organisation, the Interim Commission, which had been in being since the Hot Springs Conference, ceased to exist, and tribute is paid to the high quality of its work, which has provided sound foundations for future developments and greatly facilitated the business of the first session of the succeeding body. At the close of the Conference, membership of the Food and Agriculture Organisation consisted of forty-two countries and in addition four others were represented as observers. Sir John Boyd Orr, well known for his valuable work both in the realms of agriculture and nutrition, has been appointed director-general, and many distinguished specialists with a wide diversity of experience are among the members of the various committees. L. B. Pearson (Canada), as chairman of the first session, writes an introductory letter to the report,

* Food and Agriculture Organisation of the United Nations. Report of the First Session of the Conference held at the City of Quebec, Canada, October 16 to November 1,1945 . Pp. xxi + 89. (Washington, 6:' F:A.O., 2000 Massachusetts Avenue, N.W., 1946.) explaining the framework of the Organisation, setting forth its aims and calling upon the various governments for the necessary support to implement its recommendations.

The task before the Conference was immense and many of the recommendations are necessarily those of long-term policy. Care has been taken, however, that problems of immediate urgency should not be overlooked, for it is asserted that substantial improvements in production, nutrition and rural welfare could be effected merely by a more energetic application of existing knowledge and facilities.

The avoidance of overlapping between different organisations working in the same field is clearly desirable, and the winding up of the International Institute of Agriculture and the Comité International du Bois in favour of the Food and Agriculture Organisation is recommended. At the same time, the necessity for co-operation with any appropriate national organisation already in existence is repeatedly stressed, and the greatest importance is attached to the representation of the Organisation at all international discussions on commodity arrangements in respect of food and other agricultural products.

The work of the Conference was divided into two parts. Commission A dealt with the broad subject of policies and programmes, and consisted of six committees concerned respectively with nutrition and food management, agriculture, forestry and forest products, fisheries, marketing and statistics.

Commission $\mathrm{B}$ devoted its attention to organisation and administration, and was made up of four committees dealing with rules and procedure, finance, administrative arrangements, and constitutional and diplomatic questions respectively.

The reports of the various committees of Commission A leave no doubt as to the need for such a body as the Food and Agriculture Organisation. International co-operation and a linking together of production and consumption, and of industry with agriculture are essential if any solution is to be found for the innumerable problems of the world to-day. The fear of over-production is almost universal among Western farmers, but neither unrestricted competition nor control of output will meet the situation. Only by finding the necessary balance between production and consumption can the danger be removed. In the less developed but densely populated countries, though the immediate need is for agricultural improvements, industries must be developed to provide employment for the surplus population and raise the standard of living. A large proportion of the world's population is undernourished, quite apart from the special problems created by the Second World War, and one of the immediate tasks of the Organisation is to get needed foods to certain vulnerable groups such as young mothers and children. In these poor countries it is suggested that demonstration areas should be set up where educational schemes and food distribution can be carried out, and the production of more protective foods such as milk and vegetables be specially encouraged. Assistance with seeds, fertilizers, machines and advisory services are also a first call on the Organisation's activities in such countries. Further programmes for raising the standard of livestock and crops, irrigation and soil improvement are envisaged in the near future.

The world's undeveloped forests, especially those of tropical regions, present a unique opportunity for the Food and Agriculture Organisation. Besides being 
the greatest remaining wood reservoir in the world, they produce a great assortment of non-timber and food products. The Organisation is the only existing body that can influence Governments to develop sound policies for their utilization, thus avoiding a repetition of the wasteful exploitation that has so often occurred in the past. To this end a world forest policy is urged, such as has already been considered by the Interim Commission. Besides the direct value of the timber, good forest management has far-reaching beneficial effects. Afforestation can reclaim swampy land, prevent soil erosion, and, provided grazing is controlled, may be an asset in the raising of livestock ; in fact, over large areas afforestation is a pre-requisite to better agriculture and improved rural living standards.

Up to the present, there has been no world-wide organisation of fisheries, and the collection of information regarding world production and markets and the setting up of statistical surveys are pressing demands on the Food and Agriculture Organisation. Normally more than ninety per cent of the world's fish is caught in the North Atlantic and North Pacific Oceans, but, during the War, fishing grounds have been developed by South American countries and could probably be extended elsewhere. Freshwater fish, too, might be a valuable asset in districts where livestock industries cannot easily be developed and the diet is likely to be deficient in protein. Conservation measures are of importance in the old fisheries, and in view of the varied nature of the problems in the different areas, it is suggested that international action should be established on a regional basis.

Marketing affects all commodities, and the economic adjustment of international markets is perhaps the most crucial problem that confronts the Food and Agriculture Organisation. The under-developed countries need advice and help on the technical side of modern marketing, whereas simplification in methods of distribution is the prior call in the more advanced countries. Measures for intermational co-operation on matters of food infestation, stahdiardization of grades, nomenclature, etc., will need wxorking out, and machinery designed to deal with shortages and surpluses. The improvements in methods of processing and storage developed during the War should prove of particular benefit in the latter case.

In all these fields statistics form an essential background, and there is urgent need for the continuation and extension of international records relating to agriculture, forestry, fisheries and food consumption. Uniformity in definition of terms, together with the use of comparable techniques for the collection of data, are urged, and the formation of a central statistical unit servicing all the activities of the new Organisation is suggested.

The need for a central library, or possibly of several regional libraries, is evident, and it is hoped that the agricultural library of the International Institute of Agriculture will be available as a nucleus for the Food and Agriculture Organisation.

The documents and resolutions appended to the report are impressive evidence of the work of Commission B. They comprise a set of rules of procedure, a set of permanent and temporary financial regulations, and a budget for the first two financial years. On this Commission's recommendation, the Conference decided to continue the temporary seat of the Organisation at Washington, and to establish the permanent seat at that of the United Nations, assuming that this would also be the seat of the Economic and Social Council.

In signing the constitution of the Food and Agriculture Organisation, governments have undertaken to make periodic reports to the director. general on progress achieved in the fields of nutrition, agriculture, forestry, fisheries and rural welfare. These will provide the information from which further advice and recommendations can be given - in fact, the Organisation will be useful to the extent which it is used. In the words of the chairman, "The first of the new permanent United Nations agencies is now launched. . . . The Conference hopes that it will likewise be first in energy and in usefulness, so that it may make the maximum contribution possible to healthier and more abundant life, and to a peace built on day-by-day, practical co-operation among the peoples of the world."

\section{6}

Prof. R. T. Leiper, C.M.G., F.R.S.

THE title f of professor of helminthology has been conf $\mathrm{d}$ b the University of London upon Prof. R. T. Leiper, who is retiring from the William Juton Co rtauld chair of helminthology. When he wer. 8 the London School of Tropical Medicine (which later amalgamated with the London School of Hygiene) Leiper set himself to organise the courses of instruction in helminthology which have been so valuable to medical men taking postgraduate courses and to others who have been able to attend them. Leiper was also director of the Institute of Agricultural Parasitology at Winches Farm, St. Albans. To his inspiration and wise guidance we are largely indebted for the series of researches done at this Institute upon the nematodes which do so much harm to valuable crops and also upon the nematodes and other helminths which attack farm animals. Winches Farm, now well known wherever parasitology is studied, is also the home of the Imperial Bureau

\section{and VIEWS}

of Agricultural Parasitology, the services of which to research workers and to others can scarcely be under-estimated. Leiper also founded and edited the Journal of Helminthology, which was, until it became necessary, during the recent War, to discontinue it, one of the very few British journals devoted entirely to parasitology. Prof. Leiper's own researches take us back some forty years, when he began to publish the long series of papers in which his work is recorded. Outstanding among these papers is the record of his work on the life-histories of the human blood-flukes, Schistosoma hoematobium and S. mansoni. When Japanese workers worked out the life-history of Schistosoma japonicum, which causes human schistosomiasis in Japan and adjacent areas, Leiper set to work in Egypt, and demonstrated that $S$. hoematobium and S. mansoni are different species, which employ as their intermédiate hosts different species of snails. He thus laid the biological foundation of our present extensive know. 